\title{
Cost analysis and risk supervision of project in electric power construction
}

\author{
GU ZHENG ${ }^{1}$, LU TIANQI ${ }^{1}$, MA QIANG $^{1}$ \\ 1.State Grid Liaoning Electric Power Company Limited Economic Research Institute, , \\ Shenyang,110000, China
}

\begin{abstract}
Keywords: project cost; electric power construction; electric power enterprise; cost analysis; risk monitoring
\end{abstract}

\begin{abstract}
At present, the project cost management of most electric power construction enterprises remains in the following way: the Finance Department will judge the surplus-deficit status of the engineering in accordance with the income from engineering settlement and actual cost of engineering and make evaluation after the completion of the engineering and end of settlement. As most construction projects of the electric power construction enterprise are such state-invested projects as power plant, more investment is required and the construction period is longer and it is harder to manage than that of general engineering projects. Therefore, the method for cost analysis and risk supervision of project in electric power construction is discussed in the Thesis. Firstly, analysis is made on the cost risk of engineering project and systematic and dynamic method is adopted for the comprehensive management of the cost risk of engineering project; secondly, as the quality of technical scheme for construction influences the construction cost, scientific and advanced technology is adopted during the construction to improve construction quality and speed up construction progress; finally, project management and risk management are implemented based on the cost control of engineering project to reduce cost and achieve the maximum economic benefits and social benefits of the engineering project.
\end{abstract}

\section{Introduction}

At present, the project cost management of most electric power construction enterprises remains in the following way: the Finance Department will judge the surplus-deficit status of the engineering in accordance with the income from engineering settlement and actual cost of engineering and make evaluation after the completion of the engineering and end of settlement. However, they seldom make a deep analysis on the cause for the loss or profit of the engineering project during the construction to evaluate the implementation effect of some cost control measures in daily work management of the engineering project. Therefore, it is necessary to seek the root cause for the loss of cost during the project management of electric power construction enterprises and carry out reasonable management and control. The implementation steps for cost control of engineering project and effective ways to reduce cost will be explained below.

\section{Seek effective ways to control construction cost}

Adopt organizational measures to control engineering cost

Firstly, it is necessary to determine the organization establishment and personnel allocation of Project Manager Department and the division of authority relationship among the company, Project Manager Department and construction team. The Project Manager Department shall coordinate the relation of responsibility, right and interest between the company and construction team. Secondly, it is necessary to determine the personnel in charge of cost control and the tasks so that there is someone to be responsible for the cost control to avoid such problems as large cost, exceeding expense and undefined responsibility for the loss of project.

Adopt technical measures to control engineering cost

As the quality of technical scheme for construction influences the construction cost, scientific and advanced technology is adopted during the construction to improve construction quality and 
speed up construction progress. During the construction, conduct more than one process if possible and promptly start another process at the right time when the previous process is in such stage that another process can be started so as to appropriately arrange all processes and save time and laborer. Therefore, it is necessary to conduct necessary techno-economic verification for the main technical scheme in the bid to seek the relatively economic and reliable scheme so as to reduce engineering cost.

Strengthen quality management

During the construction, it is necessary to strictly control the engineering quality ensure that people of various types of work take the post with certificates and regularly carry out the education for safety and quality; take preventive measures and eliminate common quality problems; carry out the construction in strict accordance with the design to avoid rework due to poor quality and unnecessary cost waste. The enterprise shall pay more attention to new technologies and new materials and consider that whether the adoption of new technologies or new materials when the cost is reduced or under the same condition can improve the engineering quality so as to control the engineering cost and guarantee the engineering quality.

Strengthen contract management

Contract management is the important content for construction enterprise management and also the effective way to reduce engineering cost and improve economic benefits. The project construction contract management shall be started from contract negotiation to the end of the warranty period. It is extremely necessary to strengthen the contract management during the construction to ensure the implementation of contract.

(1) The construction enterprise shall be careful to do research on the terms of contract at the bidding phase and conduct contract analysis and raise questions to the Employer in case the terms of contract are unfavorable to the construction enterprise. After winning the bid and before the conclusion of engineering contract, it shall be careful to do research on the terms of contract and conduct the contract risk analysis based on its own conditions and characteristics and shall have the strength to solve the risk in case it occurs. The wording in the terms of contract shall be accurate and obligations, responsibilities and rights of the Employer and Contractor shall be written clearly. Do not leave any deficiency in the terms of contract due to insufficient preparation or negligence to cause difficulty to the contract performance and loss to the lawful rights and interests of the Construction Organization.

(2) Agreement on the construction period, quality and price is the most important content in the construction contract. During the construction, such phenomena as design change, on-site visa and price difference of materials will occur inevitably at the request of the Employer or engineering demand,. Therefore, the calculation basis for design change and the issue and confirmation of design change, on-site visa and material price shall be explicitly stipulated to avoid risk and realize the maximum profit.

(3) Select people with contract negotiation ability and experience to form the negotiation team. At the substantial negotiation stage of the contract, the negotiating strategies and skills are extremely important. Therefore, it is necessary to select people with contract negotiation ability and experience to carry out the contract negotiation. During the contract negotiation, the reasonable and favorable negotiation appears particularly important.

(4) During the execution of contract, it is necessary to pay abundant attention to such terms as procurement ad inspection of materials and equipment, safety management on the construction site and default responsibilities. During the contract performance, it is also necessary to promptly sign the supplemental agreement and agreement for changes to adjust the rights and obligations of all parties in accordance with the actual situation.

Strengthen cost control at construction stage

The construction enterprise has basically determined the contract price to contract the engineering through bidding and tendering and contract negotiation. At the present stage, the contracting generally has fixed total price and the engineering cost will be adjusted under the condition of engineering change and permission of other terms. Therefore, under the condition that 
the price is fixed, the actual cost expense of the enterprise determines the level of profitableness of the enterprise. The higher the cost is, the lower the profit is. If the cost is higher than the price, the survival and development of the enterprise will be endangered.

Implement talent strategy and improve scientific and technological level

The essence of market competition is the talent competition. Only attention is paid to talents and talent team is established, can the enterprise culture be formed and the enterprise development be promoted. It is necessary to do netter the project cost of the construction enterprise; strengthen the establishment of the team of technical talents; improve the overall quality and cultivate a group of inter-disciplinary talents with such professional knowledge as economy, finance and accounting, project management, contract management and risk management.

The enterprise has to have a comprehensive understanding of and implement the thought that science and technology are the primary productive forces and rapidly advocate and encourage the good ethos that all staff study science and use science and technology inside the enterprise. It shall also evaluate the practicability of new materials, new processes and new technologies and the benefits brought about through the application of them and actively apply new processes, new technologies and new materials to provide technical guarantee for the engineering.

\section{Strengthen the project cost supervision}

The engineering project cost supervision is an important constituent part of the internal financial management of the enterprise and also the effective method to control engineering project cost. The standardization of effective engineering project cost supervision mechanism can prevent and resolve financial risk and reduce construction cost and also improve the economic benefits of the enterprise.

(1) Establish financial supervision center and designate specially-assigned person to be responsible for the supervision to ensure the effective implementation of various financial management systems. Complete the internal control system of the enterprise to make various economic activities at each links free of the carrier of false reflection and operation against regulations. Formulate regulations on the supervision and management of engineering project cost suitable for the actual situation of the enterprise and completely eradicate the occurrence of events against regulations from the source and procedure.

(2) Strictly carry out the system for the monitoring of fund flow statement to carry out remote monitoring on the use of funds, cost control, settlement, handover of funds, debt, recovery rate of funds of the Employer and preventive and control measures for risk and further deepen and expand it to strengthen the stiffness of cost control.

(3) Establish the early warning mechanism for the risk control of engineering project cost and strengthen the supervision and control of control risk of the engineering project cost to guide the operating activities of the enterprise and give early warning for the possible risk of fund flow so as to guarantee that the operating activities of the enterprise remain in the controllable condition or under the control and effectively improve the ability to prevent various financial risks of the enterprise. Strengthen the forecast before the event, control during the event and analysis after the event and assist the leadership to promptly make decisions, coordinate the fund, resolve financial risk and optimize the capital structure to provide valuable information for the decision-making level to adjust the operating strategy.

(4) Under the precondition of implementing the comprehensive engineering project cost supervision, it is necessary to conduct overall evaluation on the operating performance after the completion of the project. On one hand, objectively evaluate whether the engineering project reaches the expected economic benefits; on the other hand, put forward opinions and suggestions for the operation management of the engineering project of the same kind. 


\section{Conclusions}

The cost analysis and control and risk supervision in electric power construction shall be started from the following points: to conduct effective engineering cost control, it is necessary to take measures from such aspects as organization, technology, economy, contract and information management and determine the project organization structure and the expense control shall be in the charge of the specially-assigned person and determine the function division of management. Attach importance to the design of multiple schemes and strictly review and supervise the preliminary design, technical design, construction drawing design, construction management plan and go deep into the research on the possibility of investment saving from the technical aspect. Make a dynamic comparison between the planned value and actual value of investment and strictly audit various expenses. For the purpose of improving project investment benefits, it is necessary to combine technology and economy during the engineering construction and accurately treat the relationship between advanced technology and reasonable economy through technology comparison, economic analysis and effectiveness evaluation to achieve the economic reasonableness under the condition of advanced technology as well as the advanced technology on the basis of economic reasonableness to penetrate the concept to control project investment into various designs and technical measures for construction.

\section{Reference}

[1] $\mathrm{Vu} \mathrm{H} \mathrm{A,} \mathrm{Wang} \mathrm{J,} \mathrm{Min} \mathrm{L,} \mathrm{et} \mathrm{al.} \mathrm{Research} \mathrm{on} \mathrm{Cost} \mathrm{Overrun} \mathrm{Risk} \mathrm{of} \mathrm{Construction} \mathrm{Phase} \mathrm{of}$ Vietnam Highway International Contracting Project[J]. Engineering, 2016, 08(3):86-98.

[2] Liu W H. Discussion on Risk Prevention in Supervision of Power Grid Projects Construction[J]. Henan Electric Power, 2009.

[3] Zeng X, Chen J. Evolutionary Game Analysis and Countermeasure Study of Construction Enterprises Safety Supervision in China[M]// Proceedings of the 19th International Symposium on Advancement of Construction Management and Real Estate. Springer Berlin Heidelberg, 2015:771-786.

[4] Lv, Z., Halawani, A., Feng, S., Li, H., \& Réhman, S. U. (2014). Multimodal hand and foot gesture interaction for handheld devices. ACM Transactions on Multimedia Computing, Communications, and Applications (TOMM), 11(1s), 10. 